\title{
The Role of Social Media in Enhancing Clinical Trial Recruitment: Scoping Review
}

Ida Darmawan ${ }^{1}$, MA; Caitlin Bakker ${ }^{2}$, MLIS, AHIP; Tabetha A Brockman ${ }^{3,4}$, MA; Christi A Patten ${ }^{3,4}$, PhD; Milton Eder $^{5,6}, \mathrm{PhD}$

${ }^{1}$ Hubbard School of Journalism and Mass Communication, University of Minnesota, Minneapolis, MN, United States

${ }^{2}$ Health Sciences Libraries, University of Minnesota, Minneapolis, MN, United States

${ }^{3}$ Department of Psychiatry and Psychology, Mayo Clinic, Rochester, MN, United States

${ }^{4}$ Center for Clinical and Translational Science, Mayo Clinic, Rochester, MN, United States

${ }^{5}$ Department of Family Medicine \& Community Health, University of Minnesota, Minneapolis, MN, United States

${ }^{6}$ Clinical and Translational Science Institute, University of Minnesota, Minneapolis, MN, United States

\section{Corresponding Author:}

Ida Darmawan, MA

Hubbard School of Journalism and Mass Communication

University of Minnesota

206 Church St SE

Minneapolis, MN, 55455

United States

Phone: 16127358974

Email: darma002@umn.edu

\section{Abstract}

Background: Recruiting participants into clinical trials continues to be a challenge, which can result in study delay or termination. Recent studies have used social media to enhance recruitment outcomes. An assessment of the literature on the use of social media for this purpose is required.

Objective: This study aims to answer the following questions: (1) How is the use of social media, in combination with traditional approaches to enhance clinical trial recruitment and enrollment, represented in the literature? and (2) Do the data on recruitment and enrollment outcomes presented in the literature allow for comparison across studies?

Methods: We conducted a comprehensive literature search across 7 platforms to identify clinical trials that combined social media and traditional methods to recruit patients. Study and participant characteristics, recruitment methods, and recruitment outcomes were evaluated and compared.

Results: We identified 2371 titles and abstracts through our systematic search. Of these, we assessed 95 full papers and determined that 33 studies met the inclusion criteria. A total of 17 studies reported enrollment outcomes, of which 9 achieved or exceeded their enrollment target. The proportion of participants enrolled from social media in these studies ranged from $0 \%$ to $49 \%$. Across all 33 studies, the proportion of participants recruited and enrolled from social media varied greatly. A total of 9 studies reported higher enrollment rates from social media than any other methods, and 4 studies reported the lowest cost per enrolled participant from social media.

Conclusions: While the assessment of the use of social media to improve clinical trial participation is hindered by reporting inconsistencies, preliminary data suggest that social media can increase participation and reduce per-participant cost. The adoption of consistent standards for reporting recruitment and enrollment outcomes is required to advance our understanding and use of social media to support clinical trial success.

(J Med Internet Res 2020;22(10):e22810) doi: $\underline{10.2196 / 22810}$

\section{KEYWORDS}

social media; clinical trial; recruitment methods; enrollment methods; review 


\section{Introduction}

Patient recruitment continues to be a major challenge in clinical trials, with $19 \%$ of trials being terminated due to poor recruitment and another one-third needing to extend recruitment time [1,2]. Delay and termination of clinical trials has significant scientific, ethical, and financial impact on patients, researchers, and society [3]. Termination of clinical trials due to recruitment issues leads to failure to obtain the necessary evidence to assess efficacy, safety, and effectiveness of an intervention, which could subsequently delay the implementation of a more beneficial therapy or allow an existing suboptimal standard therapy to remain in practice $[3,4]$. From an ethical perspective, study termination exposes enrolled patients to unnecessary risks and inconvenience due to the impossibility of generating sufficient data [3]. Furthermore, delay and termination also involve human, time, and financial opportunity costs, lower researchers' morale, and may reduce society's trust and subsequent willingness to participate in medical research [3].

Multiple factors contribute to recruitment failure in clinical trials, including lack of funds, complex and unclear trial design, and failure to find and interest eligible participants [5]. The inability to reach potential participants may result from overestimation of prevalence, competing trials, and ineffective advertising strategies [5]. Although researchers employ multiple strategies to improve clinical trials recruitment, evidence on best practices is lacking.

In recent years, researchers have increasingly augmented traditional methods, such as newspaper, radio or television advertisements, flyers, and signs on buses, with social media strategies to help accelerate enrollment and achieve their recruitment targets. Social media may offer distinct benefits compared with traditional methods due to its ability to target specific patient segments using customized messages that may resonate better with the target segments [6]. Additionally, several social media platforms have a higher proportion of users from minority groups (eg, African American use of Twitter), which can facilitate reach and diversity of recruitment for trials [6].

Research evaluating the effectiveness of social media in enhancing clinical trial recruitment in various settings has produced conflicting results [7-10]. Some studies find social media more effective and less costly than traditional methods [7,8], while others do not [9,11]. A scoping review on the use of social media in health research recruitment published in 2016 also yielded inconclusive findings [12]. Differences in the results reported appear to be due to the ways researchers defined social media, the types of studies included in the review, and variation in how studies compared and assessed recruitment and enrollment through social media and traditional methods.

In this study, we define social media as "a group of Internet-based applications that build on the ideological and technological foundations of Web 2.0, and that allow the creation and exchange of User Generated Content" [13]. According to the Organization for Economic Co-operation and Development definition, user-generated content needs to be published on a website that is publicly accessible, show some creative effort, and not be created in the context of professional work [14]. This definition excludes online media supported by internet-based platforms, such as email, instant messaging, regular websites, replications of existing content, and work created by companies for commercial use. We define traditional methods as offline (non-internet-based) platforms, such as television, print, and in-person recruitment. By using generally accepted definitions of social and traditional media, we address the heterogeneity observed in a prior scoping review and more clearly articulate the basis for including studies in this scoping review.

The prior scoping review included both observational and interventional studies [12], which potentially confounded the results. To avoid potential incommensurability across studies, this review includes only research studies that meet the National Institutes of Health's definition of a clinical trial [15]. Beyond refinements to the inclusion criteria, new studies comparing the use of social media and traditional methods for clinical trial recruitment have been published. As a result, two-thirds of the studies included in this scoping review were not evaluated in the prior scoping review.

Our scoping review examined the literature on the use of social media in conjunction with traditional methods in clinical trials to improve recruitment outcomes (success rate and cost). Specifically, this review addressed the following questions: (1) How is the use of social media, in combination with traditional approaches to enhance clinical trial recruitment and enrollment, represented in the literature? (2) Do the data on recruitment and enrollment outcomes presented in the literature allow for comparison across studies?

\section{Methods}

\section{Review Method and Search Strategy}

A scoping review was performed and reported using the Preferred Reporting Items for Systematic Reviews and Meta-Analyses extension for scoping reviews (PRISMA-ScR) guidelines, and the checklist is provided in Multimedia Appendix 1 [16]. The protocol can be accessed through the Open Science Framework website [17]. Since this study focused on previously published literature and thus did not involve direct contact with human participants, institutional review board approval was not required [18].

We performed a comprehensive search in July 2019 using the following databases: PubMed; MEDLINE, EMBASE, and PsycInfo via Ovid; Cochrane Library via Wiley; Scopus; and Web of Science Core Collection. A combination of natural language and controlled vocabulary was employed in accordance with Methodological Expectations of Cochrane Intervention Reviews guidelines [19]. A complete search strategy is available in Multimedia Appendix 2. To ensure that we did not overlook potentially relevant items, we also reviewed reference lists of related systematic and scoping reviews and included studies. Results were compiled and deduplicated in EndNote (version X.9; Clarivate Analytics). 


\section{Inclusion and Exclusion Criteria}

Papers employing strategies according to the stated definitions of social media and traditional methods were included. Papers also needed to be a clinical trial and describe at least one of the following outcomes: number of participants recruited or enrolled, cost of recruitment, or length of recruitment. Papers that contained no original data (editorials, letters to editors, opinions, conference proceedings, comments, systematic reviews), that recruited health care professionals as participants, or that did not report outcomes of interest were excluded.

\section{Screening}

Papers were screened in 2 stages: (1) title and abstract screening and (2) full-text screening using the aforementioned inclusion and exclusion criteria. Two independent screeners reviewed papers at both the title and abstract stage and the full-text stage (ID, $\mathrm{CB}$, and $\mathrm{TAB}$ ). We resolved discrepancies through discussion and consensus or through the intervention of a third party when necessary. Study screening was facilitated using Rayyan (Qatar Computing Research Institute).

\section{Data Charting Process}

Two independent reviewers charted data using standardized collection forms created in REDCap (Vanderbilt University).
Again, discrepancies were resolved by discussion to achieve consensus. Data charted included study characteristics (goal of intervention, disease, mode of intervention), recruitment methods (social media platforms, traditional methods, other online methods), participant characteristics (age, sex, ethnicity, geographic location, type of residential area), and recruitment outcomes (number of participants recruited via each method, cost of recruitment, length of recruitment). We encountered differences in the way researchers described recruitment versus enrollment outcomes across studies. As a result, we defined recruitment as the first contact between prospective participants and study staff and enrollment as when participants were enrolled in the study after they signed informed consent. We extracted both recruitment and enrollment data when available.

\section{Results}

\section{Paper Selection}

Our search strategy identified a total of 5177 papers. After removing duplicates $(n=2806)$, the titles and abstracts of 2371 papers were screened against the exclusion criteria, resulting in 95 papers for full-text screening. From this, 64 papers did not meet inclusion criteria (Figure 1); the remaining 31 papers were included in this review and described in detail below. 
Figure 1. PRISMA flow diagram.

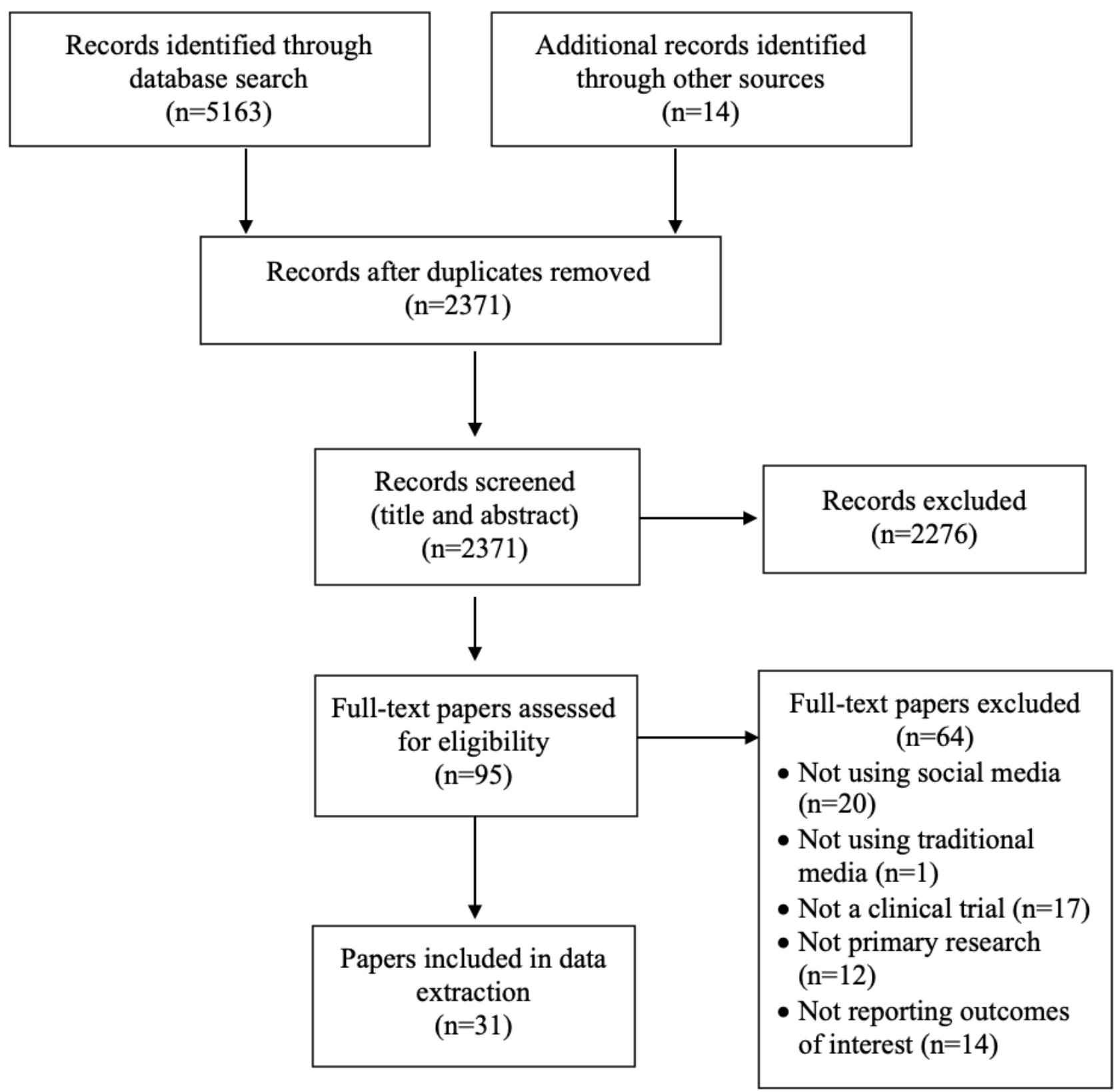

\section{Study Characteristics}

Of the 31 papers, 29 reported on a single study and 2 included reports on 2 studies each. This review identified a total of 33 studies that reported using social media and traditional methods in recruitment to clinical trials. The 33 studies described interventions for treatment $(n=19)$ and prevention $(n=14)$. A total of 19 studies consisted of in-person visits only, 10 were online only, and 4 consisted of in-person and online participation. Study diseases or conditions focused on lifestyle and behavior (eg, weight loss, smoking), neurology, obstetrics/gynecology, and HIV. Most studies (32/33) recruited adults (18 years or older), with 5 studies focusing on older adults and seniors; 1 study recruited adolescents. Detailed characteristics of included studies are presented on Table 1. 
Table 1. Characteristics of included studies.

\begin{tabular}{|c|c|c|c|c|}
\hline Study authors (year) & Purpose of intervention & Mode of intervention & Diseases or conditions & $\begin{array}{l}\text { Participant's } \\
\text { age (years) }\end{array}$ \\
\hline Abbate et al (2017) [20] & Treatment & Online & Smoking & $18+$ \\
\hline Adam et al (2016) [21] & Prevention & In-person & Weight gain and diet & $23-40$ \\
\hline Alley et al (2016) [22] & Prevention & Online & Physical activity & $18+$ \\
\hline Bracken et al (2019) [23] & Prevention & In-person & Type 2 diabetes & $50-74$ \\
\hline Buckingham et al (2017) [24] & Prevention & In-person & HIV & $18+$ \\
\hline Burrell et al (2012) [25] & Prevention & In-person & HIV & $18+$ \\
\hline Cowie et al (2018) [26] & Treatment & In-person & Alzheimer disease & $60+$ \\
\hline Frandsen et al (2014) [27] & Treatment & In-person & Smoking & $18+$ \\
\hline Frandsen et al (2016) [9] & Treatment & In-person & Smoking & $18+$ \\
\hline Guthrie et al (2019) [28] & Treatment & In-person & $\begin{array}{l}\text { Postmenopausal vulvovaginal } \\
\text { symptoms }\end{array}$ & $45-70$ \\
\hline Heffner et al (2013) [29] & Treatment & Online & Smoking & $18+$ \\
\hline Huesch et al (2018) [30] & Treatment & In-person & Bipolar disorder & $18+$ \\
\hline Ince et al (2014) [31] & Treatment & Online & Depressive symptoms & $18+$ \\
\hline Jones et al (2012) [32] & Prevention & In-person & Physical activity & $16-18^{\mathrm{a}}$ \\
\hline Jones et al (2017) [33] & Prevention & Online & HIV & $18-29$ \\
\hline Juraschek et al (2018) [34] & Prevention & Both & Cancer survivors & $18+$ \\
\hline Kayrouz et al (2016) [10] & Treatment & Online & Anxiety, depression & $18-70$ \\
\hline Kendall et al (2018) [35] & Treatment & In-person & $\begin{array}{l}\text { Chronic dizziness, chronic neck } \\
\text { pain }\end{array}$ & $65-85$ \\
\hline Kira et al (2016) [36] & Prevention & In-person & Smoking & $16+$ \\
\hline Kuhn et al (2017) [37] & Treatment & Online & PTSD $^{b}$ & $18+$ \\
\hline Nash et al (2017) [38] & Treatment & In-person & Hypertension & $18-69$ \\
\hline Partridge et al (2015) [39] & Prevention & Both & Weight gain & $18-35$ \\
\hline Rabin et al (2013) [40] & Prevention & Online & Physical activity & $18-39$ \\
\hline Raviotta et al (2016) [41] & Prevention & Both & $\mathrm{HPV}^{\mathrm{c}}$ & $18-25$ \\
\hline Rounds et al (2019) [42] & Treatment & Both & Obesity & $18-65$ \\
\hline Sanchez et al (2018a) [43] & Treatment & In-person & $\mathrm{ARHL}^{\mathrm{d}}$ & $18+$ \\
\hline Sanchez et al (2018b) [43] & Treatment & In-person & ARHL & $50-89$ \\
\hline Shere et al (2014) [44] & Treatment & In-person & Pregnancy & $18-45$ \\
\hline Usadi et al (2015a) [45] & Treatment & In-person & Infertility & $18-40$ \\
\hline Usadi et al (2015b) [45] & Treatment & In-person & Infertility & $18-40$ \\
\hline Volkova et al (2017) [46] & Prevention & Online & Healthy food purchase & $18+$ \\
\hline Waltman et al (2019) [47] & Prevention & In-person & Bone loss & $19+$ \\
\hline Watson et al (2018) [48] & Treatment & Online & Smoking & $18+$ \\
\hline
\end{tabular}

${ }^{\mathrm{a}}$ Participants were 11 th-grade students. Age range is estimated.

${ }^{b}$ PTSD: posttraumatic stress disorder.

${ }^{\mathrm{c}} \mathrm{HPV}$ : human papillomavirus.

${ }^{\mathrm{d}}$ ARHL: age-related hearing loss. 


\section{Recruitment Methods}

Facebook was the most commonly used social media platform (31/33), followed by Twitter (6/33). The majority of studies $(21 / 33)$ used a single social media platform and the remainder used two or more social media platforms, with one study reporting the use of 4 platforms. Facebook use occurred across all studies reporting the use of more than one social media platform.

Studies that reported using Facebook for their recruitment used a variety of Facebook features: Facebook ads, Facebook pages (including boosted posts on a page) [10,36], or sending a friend invite to prospective participants using a Facebook account [32]. One study used untargeted Facebook ads, then switched to targeted Facebook ads that showed ads only to participants who met the study criteria [22]. Several studies started using social media after other recruitment methods were deployed $[28,31,38,44]$, while others used social media at the beginning of their recruitment period.

The most commonly used traditional method was print (32/33), followed by in-person venues (17/33) and referrals from health care professionals (16/33). A total of 23 studies used other online media, such as website ads (15/23), emails (11/23), and Craigslist (8/23).

\section{Recruitment and Enrollment Rates}

A total of 17 out of 33 studies reported overall enrollment rates. Of these, 9 studies achieved or exceeded their enrollment target. Of these 9 studies, 8 reported the proportion of participants enrolled through social media, which ranged from $0 \%$ to $49 \%$. One study that achieved its enrollment target reported that social media outperformed other recruitment methods [48].

About half of the studies (17/33) reported both recruitment and enrollment rates from social media, 3 studies reported recruitment rates only, 11 studies reported enrollment rates, and 2 did not report either (Table 2). The proportion of participants recruited and enrolled from social media varied greatly from study to study (Table 2) and across study types (Table 3). Studies with a high proportion (50\% or greater) of participants enrolled from social media recruited adult participants. Studies recruiting seniors [26,35,43] and the 1 study involving adolescents [32] enrolled the majority of participants from traditional methods (Table 3). 
Table 2. Reported recruitment and enrollment from social media.

\begin{tabular}{|c|c|c|}
\hline Study authors (year) & Participants recruited from social media, $\mathrm{n} / \mathrm{N}(\%)^{\mathrm{a}}$ & Participants enrolled from social media, $\mathrm{n} / \mathrm{N}(\%)^{\mathrm{a}}$ \\
\hline Abbate et al (2017) [20] & $-b$ & $24 / 151(16)$ \\
\hline Adam et al (2016) [21] & $45 / 126(36)$ & $25 / 70(36)$ \\
\hline Alley et al (2016) [22] & $205 / 278(74)$ & $74 / 140(53)^{\mathrm{c}}$ \\
\hline Bracken et al (2019) [23] & $369 / 19,022(2)$ & $16 / 1007(2)$ \\
\hline Buckingham et al (2017) [24] & $598 / 1945(31)$ & $48 / 96(50)$ \\
\hline Burrell et al (2012) [25] & - & $24 / 105(23)$ \\
\hline Cowie et al (2018) [26] & $621 / 857(72)$ & - \\
\hline Frandsen et al (2014) [27] & - & $138 / 266(52)$ \\
\hline Frandsen et al (2016) [9] & $228 / 414(55)$ & $92 / 175(53)$ \\
\hline Guthrie et al (2019) [28] & $461 / 2627(18)$ & $25 / 302(8)$ \\
\hline Heffner et al (2013) [29] & - & $11 / 222(5)$ \\
\hline Huesch et al (2018) [30] & $117 / 147(80)$ & $11 / 17(65)$ \\
\hline Ince et al (2014) [31] & 227/287 (79) & $75 / 96(78)$ \\
\hline Jones et al (2012) [32] & - & $43 / 589(7)$ \\
\hline Jones et al (2017) [33] & $940 / 1435(66)$ & $153 / 247(62)$ \\
\hline Juraschek et al (2018) [34] & $24 / 121(6)$ & $4 / 121(3)$ \\
\hline Kayrouz et al (2016) [10] & - & $70 / 81(86)$ \\
\hline Kendall et al (2018) [35] & $38 / 162(23)$ & $8 / 24(33)$ \\
\hline Kira et al (2016) [36] & $1 / 74(1)$ & $1 / 24(4)$ \\
\hline Kuhn et al (2017) [37] & - & $22 / 120(18)$ \\
\hline Nash et al (2017) [38] & - & - \\
\hline Partridge et al (2015) [39] & $20 / 1181(2)$ & $5 / 250(2)$ \\
\hline Rabin et al (2013) [40] & $11 / 73(15)^{\mathrm{d}}$ & $0 / 12(0)$ \\
\hline Raviotta et al (2016) [41] & - & $44 / 220(20)$ \\
\hline Rounds et al (2019) [42] & - & $3 / 102(3)$ \\
\hline Sanchez et al (2018a) [43] & $4 / 425(1)$ & $0 / 91(0)$ \\
\hline Sanchez et al (2018b) [43] & $\mathrm{N} / \mathrm{A}^{\mathrm{e}}$ & 0/79 (0) \\
\hline Shere et al (2014) [44] & - & - \\
\hline Usadi et al (2015a) [45] & $7 / 3358(0.2)$ & N/A \\
\hline Usadi et al (2015b) [45] & $3 / 3727(0.1)$ & N/A \\
\hline Volkova et al (2017) [46] & $966 / 2448(40)$ & $584 / 1357(43)$ \\
\hline Waltman et al (2019) [47] & $838 / 3033(28)$ & $44 / 276(16)$ \\
\hline Watson et al (2018) [48] & - & 1299/2637 (49) \\
\hline
\end{tabular}

${ }^{\mathrm{a}}$ Some studies allowed participants to be counted in multiple recruitment/enrollment methods.

${ }^{b}$ Not available (not reported by original study).

${ }^{\mathrm{c}}$ Includes participants enrolled from targeted Facebook ads only.

${ }^{\mathrm{d}}$ Includes participants recruited from emails and Craigslist.

${ }^{\mathrm{e}} \mathrm{N} / \mathrm{A}$ : not applicable. Reported as N/A due to inconsistencies in recruitment and enrollment data. 
Table 3. Social media recruitment and enrollment rates by study type.

\begin{tabular}{|c|c|c|c|c|}
\hline Study type & $\begin{array}{l}\text { Studies reporting recruitment } \\
\text { rate, } \mathrm{n}\end{array}$ & $\begin{array}{l}\text { Range of participants } \\
\text { recruited from social } \\
\text { media, } \%\end{array}$ & $\begin{array}{l}\text { Studies reporting enrollment } \\
\text { rate, } \mathrm{n}\end{array}$ & $\begin{array}{l}\text { Range of participants } \\
\text { enrolled from social } \\
\text { media, \% }\end{array}$ \\
\hline \multicolumn{5}{|l|}{ Intervention purpose } \\
\hline Treatment & 10 & $0-80$ & 14 & $0-86$ \\
\hline Prevention & 10 & $1-74$ & 14 & $0-62$ \\
\hline \multicolumn{5}{|l|}{ Disease or condition type } \\
\hline Lifestyle-related & 6 & $1-74$ & 13 & $0-53$ \\
\hline Neurological & 4 & $23-80$ & 5 & $18-86$ \\
\hline $\mathrm{OB} / \mathrm{GYN}^{\mathrm{a}}$ & 4 & $0-28$ & 2 & $8-16$ \\
\hline HIV & 2 & $31-66$ & 3 & $23-62$ \\
\hline Others & 4 & $1-6$ & 5 & $0-20$ \\
\hline \multicolumn{5}{|l|}{ Mode of intervention } \\
\hline In-person & 14 & $0-80$ & 14 & $0-65$ \\
\hline Online & 4 & $15-79$ & 10 & $0-86$ \\
\hline Both & 2 & $2-6$ & 4 & $2-20$ \\
\hline \multicolumn{5}{|l|}{ Participant age group } \\
\hline Adults (18+ years) & 15 & $0-80$ & 23 & $0-86$ \\
\hline Older adults/seniors & 5 & $1-72$ & 4 & $0-33$ \\
\hline Adolescents & 0 & $-\mathrm{b}$ & 1 & 7 \\
\hline
\end{tabular}

${ }^{\mathrm{a} O B / G Y N}$ : obstetrics/gynecology.

${ }^{b}$ Not available (not reported by original study).

Out of 20 studies that reported recruitment rates by method, 7 reported higher recruitment rates from social media than from any other methods. Similarly, out of 28 studies that reported enrollment rates by method, only 9 reported higher enrollment rates using social media than any other methods (Table 4). Among the 9 studies that reported the highest enrollment rates from social media, 6 studies were for treatment (3 lifestyle-related conditions, 3 neurological) and 3 were for prevention (2 HIV, 1 lifestyle). Of the 9 studies reporting enrollment, 5 involved an online intervention and the remainder used an in-person intervention. A total of 5 of these 9 studies used Facebook only, and the rest used more than one social media platform. 
Table 4. Enrollment rates by recruitment method. ${ }^{\mathrm{a}}$

\begin{tabular}{|c|c|c|c|}
\hline Study authors (year) & Enrolled from social media, $\%$ & Enrolled from traditional methods, $\%$ & Enrolled from other online media, $\%$ \\
\hline Abbate et al (2017) [20] & 16 & 40 & 57 \\
\hline Adam et al (2016) [21] & 36 & 64 & $\mathrm{~N} / \mathrm{A}^{\mathrm{b}}$ \\
\hline Alley et al $l^{\mathrm{c}}$ (2016) [22] & $53^{\mathrm{d}}$ & $47^{\mathrm{e}}$ & N/A \\
\hline Bracken et al (2019) [23] & 2 & 94 & 1 \\
\hline Buckingham et al (2017) [24] & 50 & 26 & 24 \\
\hline Burrell et al (2012) [25] & 23 & $77^{\mathrm{e}}$ & N/A \\
\hline Frandsen et al (2014) [27] & 52 & 47 & N/A \\
\hline Frandsen et al (2016) [9] & 53 & 47 & N/A \\
\hline Guthrie et al (2019) [28] & 8 & 92 & N/A \\
\hline Heffner et al (2013) [29] & 5 & 25 & 70 \\
\hline Huesch et al (2018) [30] & 65 & 35 & N/A \\
\hline Ince et al (2014) [31] & 78 & 2 & 0 \\
\hline Jones et al (2012) [32] & 7 & 94 & N/A \\
\hline Jones et al (2017) [33] & 62 & 38 & N/A \\
\hline Juraschek et al (2018) [34] & 3 & 77 & N/A \\
\hline Kayrouz et al (2016) [10] & 86 & 14 & N/A \\
\hline Kendall et al (2018) [35] & 33 & 67 & N/A \\
\hline Kira et al (2016) [36] & 4 & 88 & N/A \\
\hline Kuhn et al (2017) [37] & 18 & 22 & 60 \\
\hline Partridge et al (2015) [39] & 2 & 71 & 25 \\
\hline Rabin et al (2013) [40] & 0 & 100 & N/A \\
\hline Raviotta et al (2016) [41] & 20 & 80 & N/A \\
\hline Rounds et al (2019) [42] & 3 & 81 & 16 \\
\hline Sanchez et al (2018a) [43] & 0 & 19 & 5 \\
\hline Sanchez et al (2018b) [43] & 0 & 53 & 4 \\
\hline Volkova et al (2017) [46] & 43 & 46 & 11 \\
\hline Waltman et al (2019) [47] & 16 & 44 & 1 \\
\hline Watson et al (2018) [48] & 49 & 11 & 39 \\
\hline
\end{tabular}

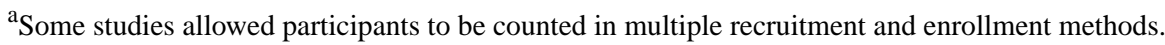

${ }^{\mathrm{b}} \mathrm{N} / \mathrm{A}$ : not applicable.

${ }^{\mathrm{c}}$ Italics signify studies that reported the highest enrollment rates from social media.

${ }^{\mathrm{d}}$ Includes participants enrolled from targeted Facebook ads only.

${ }^{\mathrm{e}}$ Includes participants enrolled from both traditional and other online media.

\section{Recruitment and Enrollment Costs}

A total of 20 studies reported itemized recruitment and enrollment costs. Of these, almost all studies reported the costs to place the recruitment ads in various media (19/20), and 6 reported the costs to develop these ads. Only 5 studies reported the costs of staff involved in participant recruitment and enrollment.
Of the 19 studies that reported cost per enrolled participant, only $4[10,21,30,33]$ reported lower cost per enrolled participant using social media than any other methods. Recruitment methods used in these 4 studies included Facebook, Instagram, print, television, radio, in-person recruitment, and website ads. Detailed costs per enrolled participant by media type can be found in Table 5. 
Table 5. Costs per enrolled participant by media type. ${ }^{\mathrm{a}}$

\begin{tabular}{|c|c|c|c|}
\hline \multirow[t]{2}{*}{ Study authors (year) } & \multicolumn{3}{|c|}{ Cost per enrolled participant } \\
\hline & Social media & Traditional methods & Other online media \\
\hline Abbate et al (2017) [20] & $\mathrm{N} / \mathrm{A}^{\mathrm{b}}$ & US $\$ 8.28^{\mathrm{c}}$ & N/A \\
\hline Adam et al (2016) [21] & Can $\$ 20.28$ & Can $\$ 24.15$ & N/A \\
\hline Bracken et al (2019) [23] & N/A & Aus $\$ 594$ & N/A \\
\hline Frandsen et al (2014) [27] & Aus $\$ 56.34$ & Aus $\$ 52.33$ & N/A \\
\hline Frandsen et al (2016) [9] & Aus $\$ 42.34$ & Aus $\$ 21.52$ & N/A \\
\hline Guthrie et al (2019) [28] & US $\$ 593$ & US $\$ 356$ & N/A \\
\hline Heffner et al (2013) [29] & US $\$ 172.76$ & US $\$ 5.27-\$ 46.98$ & US \$26.19-\$50.26 \\
\hline Huesch et al (2018) [30] & US $\$ 18$ & US $\$ 635$ & N/A \\
\hline Ince et al (2014) [31] & $€ 5.33$ & N/A & N/A \\
\hline Jones et al (2017) [33] & US \$66.46 & US $\$ 149.62$ & N/A \\
\hline Juraschek et al (2018) [34] & US $\$ 1426$ & US $\$ 436-\$ 917$ & N/A \\
\hline Kayrouz et al (2016) [10] & US $\$ 37$ & US $\$ 40$ & N/A \\
\hline Kendall et al (2018) [35] & N/A & Aus $\$ 2141^{\mathrm{c}}$ & N/A \\
\hline Nash et al (2017) [38] & Aus $\$ 45.15-\$ 176$ & N/A & N/A \\
\hline Partridge et al (2015) [39] & Aus $\$ 945.33$ & Aus $\$ 144.52-\$ 212.51$ & Aus $\$ 11.98-\$ 571.45$ \\
\hline Raviotta et al (2016) [41] & US $\$ 110$ & US $\$ 61$ & N/A \\
\hline Volkova et al (2017) [46] & $\mathrm{NZ} \$ 5^{\mathrm{d}}$ & NZ \$4-\$179 & $\mathrm{NZ} \$ 4$ \\
\hline Waltman et al (2019) [47] & US $\$ 119.38$ & US \$29.36-\$926.90 & US $\$ 1000$ \\
\hline Watson et al (2018) [48] & US \$40.51 & US $\$ 20.30$ & US $\$ 13.95-34.71$ \\
\hline
\end{tabular}

${ }^{\mathrm{a}}$ Currency exchange rates of Can $\$ 1=\mathrm{US} \$ 0.75$, Aus $\$ 1=\mathrm{US} \$ 0.72, € 1=\mathrm{US} \$ 1.17$, and NZ $\$ 1=\mathrm{US} \$ 0.66$ were applicable at the time of publication.

${ }^{\mathrm{b}} \mathrm{N} / \mathrm{A}$ : not applicable.

${ }^{\mathrm{c}}$ Cost per enrolled participant across all media.

${ }^{\mathrm{d}}$ Includes cost using Craigslist.

\section{Discussion}

\section{Principal Findings}

This scoping review examines literature describing the use of social media and traditional methods as well as other online media in clinical trial recruitment. We found that using social media resulted in the highest recruitment rates in 7 of 20 studies and the highest enrollment rate in 9 of 28 studies. We also found that social media resulted in the lowest cost per enrolled participant in 4 of 19 studies. However, the data reported about social media outcomes varied greatly across studies, obscuring our ability to evaluate if particular studies might benefit more from using social media.

Our review discovered a lack of consistency in defining and reporting recruitment and enrollment data across studies. Several studies seemed to use these terms interchangeably, and some failed to specify which data they reported (eg, when consent occurred). Furthermore, we noted inconsistencies resulting from the varied use of social media, even within a platform, and the opportunistic use of social media by several studies that started using social media only after traditional methods failed to achieve sufficient interest and enrollment. We also observed that some studies did not indicate how many participants were counted as being reached by more than one recruitment or enrollment method. Lastly, we observed inconsistencies in cost reporting, with some studies reporting itemized costs and others reporting aggregated costs. Collectively, these inconsistencies contributed to the variations in describing the outcomes of using social media and traditional methods to support clinical trial recruitment and enrollment. The inconsistencies in reporting also rendered comparison of data across the studies included in this scoping review impossible.

To address these inconsistencies, we recommend that future studies use the terms "recruitment" and "enrollment" in alignment with the definitions used by the Food and Drug Administration's advisory committee [49]. The term "recruitment" should report on all interactions with potential study participants prior to obtaining informed consent, while the term "enrollment" should report only on the total number of individuals who provide informed consent. Studies should report recruitment using as the denominator the total number of participants reached and as numerators the number of study participants reached through each method. Enrollment rates should be calculated using as the denominator the total number of participants providing informed consent and as numerators 
the number of participants enrolled through each recruitment method. Additionally, screening that results in the exclusion of participants after they provide informed consent should be reported separately, enabling a more accurate count and cost of the individuals actively participating in the intervention. Using consistent definitions of key terms across research studies will allow researchers to improve the clarity and comparability of clinical trial management data. Establishing reporting standards will also allow researchers to adopt evidence-based recruitment strategies by choosing optimal recruitment methods to reduce cost and timelines [50].

To facilitate shared learning based on the experience of prior research, we further recommend that future studies report in detail their approaches to using each social media platform (eg, Facebook ad, Facebook page) and specify the number of participants recruited or enrolled from multiple methods, which will allow for more accurate response analyses and cost estimates. As the ability to capitalize on existing social media relationships may influence both the success of recruitment and enrollment as well as their subsequent costs, researchers should consider explicitly stating whether their social media recruitment strategies are related to a larger social media initiative.

When adding social media to existing recruitment methods, researchers should report both the incremental costs of social media and the personnel cost to develop and monitor posted content. Furthermore, researchers are encouraged to report trade-offs between cost and time when analyzing the effectiveness of each recruitment method. For example, social media may result in higher cost per enrolled participant but reduce the time to enroll participants. Although we recognize the complexity in analyzing and comparing cost in different time increments and the potential for historical trends to confound results, such reporting may provide deeper insights on different recruitment methods. Such analyses may help researchers, organizations, and corporations determine whether to build social media expertise directly into their research teams to optimize the full extent of social media capabilities or to engage social media experts as consultants. The costs associated with such arrangements should be identified and, ideally, reported.

\section{Comparison With Prior Work}

The mixed results on the use of social media found in this study are similar to those found in a prior scoping review [12]. While the prior scoping review attributed the different success rates to the effort researchers put into the use of social media as a recruitment method, we found that the variations in the use of social media and the inconsistencies in the way outcomes were reported prevented comparisons across studies. Having explored the ways researchers used and reported the use of social media in clinical trial recruitment, this study advances recommendations for achieving data consistency in reporting, which would facilitate comparison across results.

Similar to the findings from a systematic mapping study conducted by Frampton et al [51], we found that the use of social media to recruit participants involved a variety of diseases and health conditions. We also failed to find many studies involving minority populations (eg, African American or lesbian, gay, bisexual, transgender, and queer populations). As a result, we are unable to provide any insights on the use of social media to recruit diverse populations when compared with traditional recruitment methods.

\section{Limitations}

Our scoping review is limited in its examination of data from clinical trials that combined social media and traditional methods in their recruitment strategies because we cannot guarantee that the review identified all relevant studies. We also cannot claim this review is comprehensive, as research not organized or reported as a clinical trial may inform reasoning about incorporating social media into the research recruitment armamentarium. The relatively recent use of social media also renders highly speculative any conclusions drawn about its appropriateness in recruitment and enrollment methods for particular diseases and conditions. We also recognize a limitation in our ability to assess the quality of the recruitment strategy, the recruitment materials, or the enrollment process. However, we advance recommendations to improve consistency in reporting on recruitment and enrollment that we believe to be necessary precursors for comparative analysis.

\section{Conclusions}

The use of social media for clinical trial recruitment holds great promise. However, this scoping review identified continued inconsistency in reports on the use of social media for clinical trial recruitment and enrollment. We recommend that future studies incorporate the recommendations for collecting and reporting recruitment and enrollment data advanced here to facilitate comparison of study data and shared learning.

\section{Acknowledgments}

This project was supported by grant number UL1 TR002494 and UL1 TR002377 from the National Center for Advancing Translational Sciences. Its contents are solely the responsibility of the authors and do not necessarily represent the official views of the National Institutes of Health.

\section{Authors' Contributions}

ID developed the project concept, performed database searches, screened papers, extracted data, analyzed social media use and recruitment and enrollment outcomes across studies, and was the lead in writing the manuscript. CB and TAB refined the project concept, screened papers, extracted data, and were major contributors in writing the manuscript. CAP was a major contributor in writing the manuscript. ME developed the project concept, analyzed recruitment and enrollment outcomes across studies, and was a major contributor in writing the manuscript. 


\section{Conflicts of Interest}

None declared.

\section{Multimedia Appendix 1}

PRISMA-ScR checklist.

[PDF File (Adobe PDF File), 103 KB-Multimedia Appendix 1]

\section{Multimedia Appendix 2}

Complete search strategy.

[XLSX File (Microsoft Excel File), 9 KB-Multimedia Appendix 2]

\section{References}

1. Campbell MK, Snowdon C, Francis D, Elbourne D, McDonald AM, Knight R, STEPS group. Recruitment to randomised trials: strategies for trial enrollment and participation study. The STEPS study. Health Technol Assess 2007 Nov;11(48):iii, ix-iii,105 [FREE Full text] [doi: 10.3310/hta11480] [Medline: 17999843]

2. Carlisle B, Kimmelman J, Ramsay T, MacKinnon N. Unsuccessful trial accrual and human subjects protections: an empirical analysis of recently closed trials. Clin Trials 2015 Feb;12(1):77-83 [FREE Full text] [doi: 10.1177/1740774514558307] [Medline: 25475878]

3. Malmqvist E, Juth N, Lynöe N, Helgesson G. Early stopping of clinical trials: charting the ethical terrain. Kennedy Inst Ethics J 2011 Mar;21(1):51-78. [doi: 10.1353/ken.2011.0002] [Medline: 21598846]

4. Task Force of the Working Group on Arrhythmias of the European Society of Cardiology. The early termination of clinical trials: causes, consequences, and control. With special reference to trials in the field of arrhythmias and sudden death. Circulation 1994 Jun;89(6):2892-2907. [doi: 10.1161/01.cir.89.6.2892] [Medline: $\underline{\text { 8205706] }}$

5. Briel M, Olu KK, von Elm E, Kasenda B, Alturki R, Agarwal A, et al. A systematic review of discontinued trials suggested that most reasons for recruitment failure were preventable. J Clin Epidemiol 2016 Dec;80:8-15. [doi: 10.1016/j.jclinepi.2016.07.016] [Medline: 27498376]

6. Caplan A, Friesen P. Health disparities and clinical trial recruitment: Is there a duty to tweet? PLoS Biol 2017 Mar;15(3):e2002040 [FREE Full text] [doi: 10.1371/journal.pbio.2002040] [Medline: 28249024]

7. Guillory J, Wiant KF, Farrelly M, Fiacco L, Alam I, Hoffman L, et al. Recruiting Hard-to-Reach Populations for Survey Research: Using Facebook and Instagram Advertisements and In-Person Intercept in LGBT Bars and Nightclubs to Recruit LGBT Young Adults. J Med Internet Res 2018 Jun 18;20(6):e197 [FREE Full text] [doi: 10.2196/jmir.9461] [Medline: 29914861]

8. Admon L, Haefner JK, Kolenic GE, Chang T, Davis MM, Moniz MH. Recruiting Pregnant Patients for Survey Research: A Head to Head Comparison of Social Media-Based Versus Clinic-Based Approaches. J Med Internet Res 2016 Dec 21;18(12):e326 [FREE Full text] [doi: 10.2196/jmir.6593] [Medline: 28003174]

9. Frandsen M, Thow M, Ferguson SG. The Effectiveness Of Social Media (Facebook) Compared With More Traditional Advertising Methods for Recruiting Eligible Participants To Health Research Studies: A Randomized, Controlled Clinical Trial. JMIR Res Protoc 2016 Aug 10;5(3):e161 [FREE Full text] [doi: 10.2196/resprot.5747] [Medline: 27511829]

10. Kayrouz R, Dear BF, Karin E, Titov N. Facebook as an effective recruitment strategy for mental health research of hard to reach populations. Internet Interv 2016 May;4:1-10 [FREE Full text] [doi: 10.1016/j.invent.2016.01.001] [Medline: $\underline{30135786}$

11. Moreno MA, Waite A, Pumper M, Colburn T, Holm M, Mendoza J. Recruiting Adolescent Research Participants: In-Person Compared to Social Media Approaches. Cyberpsychol Behav Soc Netw 2017 Jan;20(1):64-67. [doi: 10.1089/cyber.2016.0319] [Medline: 27976951]

12. Topolovec-Vranic J, Natarajan K. The Use of Social Media in Recruitment for Medical Research Studies: A Scoping Review. J Med Internet Res 2016 Nov 07;18(11):e286 [FREE Full text] [doi: 10.2196/jmir.5698] [Medline: 27821383]

13. Kaplan AM, Haenlein M. Users of the world, unite! The challenges and opportunities of Social Media. Business Horizons 2010 Jan;53(1):59-68. [doi: 10.1016/j.bushor.2009.09.003]

14. Organisation for Economic Co-operation and Development. Participative web and user-created content: Web 2.0, wikis and social networking. Organisation for Economic Co-operation and Development. 2007. URL: https://www.oecd-ilibrary.org/ science-and-technology/participative-web-and-user-created-content 9789264037472-en [accessed 2020-10-02]

15. NIH's Definition of a Clinical Trial. National Institutes of Health. URL: https://grants.nih.gov/policy/clinical-trials/definition. htm [accessed 2019-12-11]

16. Tricco AC, Lillie E, Zarin W, O'Brien KK, Colquhoun H, Levac D, et al. PRISMA Extension for Scoping Reviews (PRISMA-ScR): Checklist and Explanation. Ann Intern Med 2018 Oct 02;169(7):467-473 [FREE Full text] [doi: 10.7326/M18-0850] [Medline: $\underline{\text { 30178033] }}$ 
17. Darmawan I, Bakker C, Brockman T, Eder M. The role of social media in enhancing clinical trial recruitment - A scoping review. Open Science Framework. 2019. URL: https://osf.io/hr6sa/ [accessed 2020-10-03]

18. Part 46 - Protection of Human Subjects. Electronic Code of Federal Regulations. 2018 Jul 19. URL: https://www.ecfr.gov/ cgi-bin/retrieveECFR?gp=\&SID=83cd09e1c0f5c6937cd9d7513160fc3f \&pitd=20180719\&n=pt45.1. 46\&r=PART\&ty=HTML\# top [accessed 2020-10-02]

19. Methodological Expectations of Cochrane Intervention Reviews. Cochrane Methods. URL: https://methods.cochrane.org/ methodological-expectations-cochrane-intervention-reviews [accessed 2020-10-02]

20. Abbate KJ, Hingle MD, Armin J, Giacobbi P, Gordon JS. Recruiting Women to a Mobile Health Smoking Cessation Trial: Low- and No-Cost Strategies. JMIR Res Protoc 2017 Nov 03;6(11):e219 [FREE Full text] [doi: 10.2196/resprot.7356] [Medline: 29101091]

21. Adam LM, Manca DP, Bell RC. Can Facebook Be Used for Research? Experiences Using Facebook to Recruit Pregnant Women for a Randomized Controlled Trial. J Med Internet Res 2016 Sep 21;18(9):e250 [FREE Full text] [doi: 10.2196/jmir.6404] [Medline: 27655184]

22. Alley S, Jennings C, Plotnikoff R, Vandelanotte C. An evaluation of web- and print-based methods to attract people to a physical activity intervention. Journal of Science and Medicine in Sport 2015 Dec;19:e81 [FREE Full text] [doi: 10.1016/j.jsams.2015.12.196]

23. Bracken K, Hague W, Keech A, Conway A, Handelsman DJ, Grossmann M, et al. Recruitment of men to a multi-centre diabetes prevention trial: an evaluation of traditional and online promotional strategies. Trials 2019 Jun 19;20(1):366 [FREE Full text] [doi: 10.1186/s13063-019-3485-2] [Medline: 31217024$]$

24. Buckingham L, Becher J, Voytek C, Fiore D, Dunbar D, Davis-Vogel A, et al. Going social: Success in online recruitment of men who have sex with men for prevention HIV vaccine research. Vaccine 2017 Jun 14;35(27):3498-3505 [FREE Full text] [doi: 10.1016/j.vaccine.2017.05.002] [Medline: 28526330]

25. Burrell ER, Pines HA, Robbie E, Coleman L, Murphy RD, Hess KL, et al. Use of the location-based social networking application GRINDR as a recruitment tool in rectal microbicide development research. AIDS Behav 2012 Oct;16(7):1816-1820 [FREE Full text] [doi: 10.1007/s10461-012-0277-z] [Medline: 22851153]

26. Cowie JM, Gurney ME. The Use of Facebook Advertising to Recruit Healthy Elderly People for a Clinical Trial: Baseline Metrics. JMIR Res Protoc 2018 Jan 24;7(1):e20 [FREE Full text] [doi: 10.2196/resprot.7918] [Medline: 29367186]

27. Frandsen M, Walters J, Ferguson SG. Exploring the viability of using online social media advertising as a recruitment method for smoking cessation clinical trials. Nicotine Tob Res 2014 Feb;16(2):247-251. [doi: 10.1093/ntr/ntt157] [Medline: 24127266]

28. Guthrie KA, Caan B, Diem S, Ensrud KE, Greaves SR, Larson JC, et al. Facebook advertising for recruitment of midlife women with bothersome vaginal symptoms: A pilot study. Clin Trials 2019 Oct;16(5):476-480. [doi: 10.1177/1740774519846862] [Medline: $\underline{31055949]}$

29. Heffner JL, Wyszynski CM, Comstock B, Mercer LD, Bricker J. Overcoming recruitment challenges of web-based interventions for tobacco use: the case of web-based acceptance and commitment therapy for smoking cessation. Addict Behav 2013 Oct;38(10):2473-2476 [FREE Full text] [doi: 10.1016/j.addbeh.2013.05.004] [Medline: 23770645]

30. Huesch MD, Mukherjee D, Saunders EF. E-recruitment into a bipolar disorder trial using Facebook tailored advertising. Clin Trials 2018 Oct;15(5):522-523. [doi: 10.1177/1740774518784018] [Medline: 29952243]

31. Ünlü Ince B, Cuijpers P, van 't Hof E, Riper H. Reaching and recruiting Turkish migrants for a clinical trial through Facebook: A process evaluation. Internet Interventions 2014 Apr;1(2):74-83. [doi: 10.1016/j.invent.2014.05.003]

32. Jones L, Saksvig BI, Grieser M, Young DR. Recruiting adolescent girls into a follow-up study: benefits of using a social networking website. Contemp Clin Trials 2012 Mar;33(2):268-272 [FREE Full text] [doi: 10.1016/j.cct.2011.10.011] [Medline: 22101207]

33. Jones R, Lacroix LJ, Porcher E. Facebook Advertising to Recruit Young, Urban Women into an HIV Prevention Clinical Trial. AIDS Behav 2017 Nov;21(11):3141-3153 [FREE Full text] [doi: 10.1007/s10461-017-1797-3] [Medline: 28528463]

34. Juraschek SP, Plante TB, Charleston J, Miller ER, Yeh H, Appel LJ, et al. Use of online recruitment strategies in a randomized trial of cancer survivors. Clin Trials 2018 Apr;15(2):130-138 [FREE Full text] [doi: 10.1177/1740774517745829] [Medline: 29361843]

35. Kendall JC, French SD, Hartvigsen J, Azari MF. Chiropractic treatment including instrument-assisted manipulation for non-specific dizziness and neck pain in community-dwelling older people: a feasibility randomised sham-controlled trial. Chiropr Man Therap 2018;26:14 [FREE Full text] [doi: 10.1186/s12998-018-0183-1] [Medline: 29760878]

36. Kira A, Glover M, Walker N, Bauld L. Recruiting Pregnant Indigenous Women Who Smoke into a High Contact Incentivized Cessation Trial: A Feasibility Study. Nicotine Tob Res 2016 Oct;18(10):2036-2040. [doi: 10.1093/ntr/ntw106] [Medline: $\underline{27154970]}$

37. Kuhn E, Kanuri N, Hoffman JE, Garvert DW, Ruzek JI, Taylor CB. A randomized controlled trial of a smartphone app for posttraumatic stress disorder symptoms. J Consult Clin Psychol 2017 Mar;85(3):267-273. [doi: 10.1037/ccp0000163] [Medline: 28221061] 
38. Nash EL, Gilroy D, Srikusalanukul W, Abhayaratna WP, Stanton T, Mitchell G, et al. Facebook advertising for participant recruitment into a blood pressure clinical trial. J Hypertens 2017 Dec;35(12):2527-2531. [doi: 10.1097/HJH.0000000000001477] [Medline: 28704263]

39. Partridge SR, Balestracci K, Wong AT, Hebden L, McGeechan K, Denney-Wilson E, et al. Effective Strategies to Recruit Young Adults Into the TXT2BFiT mHealth Randomized Controlled Trial for Weight Gain Prevention. JMIR Res Protoc 2015 Jun 05;4(2):e66 [FREE Full text] [doi: 10.2196/resprot.4268] [Medline: 26048581]

40. Rabin C, Horowitz S, Marcus B. Recruiting young adult cancer survivors for behavioral research. J Clin Psychol Med Settings 2013 Mar;20(1):33-36 [FREE Full text] [doi: 10.1007/s10880-012-9317-0] [Medline: 22810954]

41. Raviotta JM, Nowalk MP, Lin CJ, Huang H, Zimmerman RK. Using Facebook ${ }^{\mathrm{TM}}$ to Recruit College-Age Men for a Human Papillomavirus Vaccine Trial. Am J Mens Health 2016 Mar;10(2):110-119 [FREE Full text] [doi: 10.1177/1557988314557563] [Medline: 25389213]

42. Rounds T, Harvey J. Enrollment Challenges: Recruiting Men to Weight Loss Interventions. Am J Mens Health 2019;13(1):1557988319832120 [FREE Full text] [doi: 10.1177/1557988319832120] [Medline: 30789079$]$

43. Sanchez VA, Hall DA, Millar B, Escabi CD, Sharman A, Watson J, et al. Recruiting ENT and Audiology patients into pharmaceutical trials: evaluating the multi-centre experience in the UK and USA. Int J Audiol 2018 Sep;57(sup4):S55-S66. [doi: 10.1080/14992027.2018.1425002] [Medline: 29355055]

44. Shere M, Zhao XY, Koren G. The role of social media in recruiting for clinical trials in pregnancy. PLoS One 2014 Mar;9(3):e92744 [FREE Full text] [doi: 10.1371/journal.pone.0092744] [Medline: 24671210]

45. Usadi RS, Diamond MP, Legro RS, Schlaff WD, Hansen KR, Casson P, Reproductive Medicine Network. Recruitment strategies in two reproductive medicine network infertility trials. Contemp Clin Trials 2015 Nov;45(Pt B):196-200 [FREE Full text] [doi: 10.1016/j.cct.2015.09.010] [Medline: 26386293]

46. Volkova E, Michie J, Corrigan C, Sundborn G, Eyles H, Jiang Y, et al. Effectiveness of recruitment to a smartphone-delivered nutrition intervention in New Zealand: analysis of a randomised controlled trial. BMJ Open 2017 Jul 02;7(6):e016198 [FREE Full text] [doi: 10.1136/bmjopen-2017-016198] [Medline: 28674144]

47. Waltman NL, Smith KM, Kupzyk KA, Lappe JM, Mack LR, Bilek LD. Approaches to Recruitment of Postmenopausal Women for a Community-Based Study. Nursing Research 2019;68(4):307-316. [doi: 10.1097/nnr.0000000000000356]

48. Watson NL, Mull KE, Heffner JL, McClure JB, Bricker JB. Participant Recruitment and Retention in Remote eHealth Intervention Trials: Methods and Lessons Learned From a Large Randomized Controlled Trial of Two Web-Based Smoking Interventions. J Med Internet Res 2018 Aug 24;20(8):e10351 [FREE Full text] [doi: 10.2196/10351] [Medline: 30143479]

49. Glossary of Terms on Clinical Trials for Patient Engagement Advisory Committee Meeting. Food and Drug Administration. URL: https://www.fda.gov/media/108378/download [accessed 2020-10-02]

50. Reuter K. Social Media for Clinical Trial Recruitment: How Real is the Potential? EMJ Innov 2020;4(1):34-39 [FREE Full text]

51. Frampton GK, Shepherd J, Pickett K, Griffiths G, Wyatt JC. Digital tools for the recruitment and retention of participants in randomised controlled trials: a systematic map. Trials 2020 Jun 05;21(1):478 [FREE Full text] [doi: 10.1186/s13063-020-04358-3] [Medline: $\underline{\text { 32498690] }}$

\section{Abbreviations}

PRISMA-ScR: Preferred Reporting Items for Systematic Reviews and Meta-Analyses extension for scoping reviews

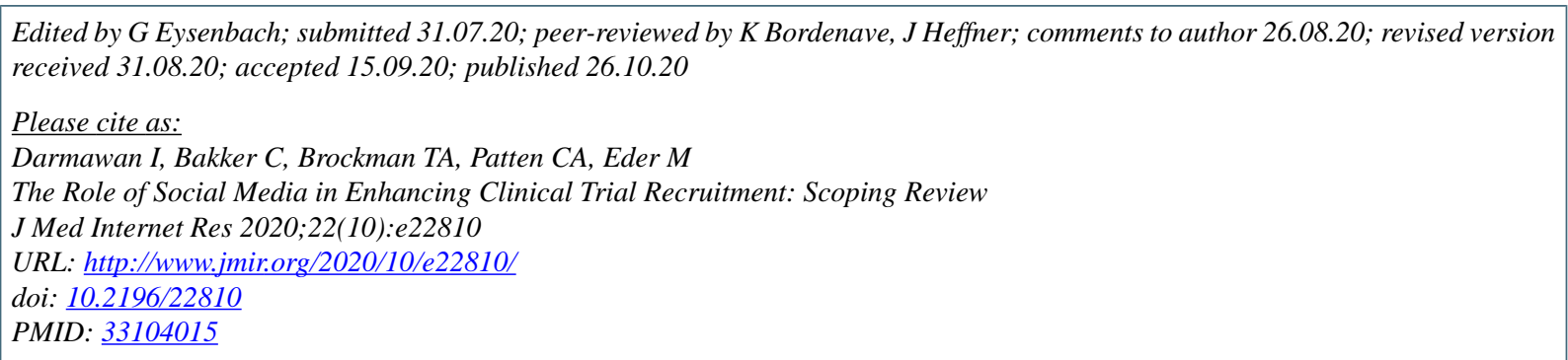

CIda Darmawan, Caitlin Bakker, Tabetha A Brockman, Christi A Patten, Milton Eder. Originally published in the Journal of Medical Internet Research (http://www.jmir.org), 26.10.2020. This is an open-access article distributed under the terms of the Creative Commons Attribution License (https://creativecommons.org/licenses/by/4.0/), which permits unrestricted use, distribution, and reproduction in any medium, provided the original work, first published in the Journal of Medical Internet Research, is 
properly cited. The complete bibliographic information, a link to the original publication on http://www.jmir.org/, as well as this copyright and license information must be included. 